\title{
Alternatif Pengembangan Diri Anak Melalui Layanan BK di Homeschooling
}

\author{
1) Universitas Pancasakti Tegal \\ 2) Universitas Pancasakti Tegal \\ 3) Universitas Pancasakti Tegal
}

Sesya Dias Mumpuni, Sukoco KW, Hastin Budisiwi

\begin{abstract}
Abstrak
Beberapa sekolah di Indonesia sudah memiliki alternatif sekolah yang dapat membantu anak belajar sesuai dengan dirinya. Salah satunya yaitu melalui homeschooling. Penelitian ini dilakukan dengan metode mixed method yaitu dengan perpaduan data kuantitatif dan kualitatif. Data kuantitatif diperoleh dari responden yang mengetahui adanya homeschooling dan perlunya layanan Bimbingan dan Konseling (BK) pada anak homeschooling. Sample responden berjumlah 20 orang yang mewakili dari keseluruhan responden yaitu masyarakat laki-laki dan perempuan dalam rentang usia 20 - 50 tahun yang berlokasi di Kota Tegal dan sekitarnya yang mengetahui keberadaan homeschooling. Pengambilan data dilakukan dalam rentang waktu dua bulan. Dari skala yang digunakan adalah jenis skala Lickert yang dianalisis menggunakan product moment dan Alpha Krombultz. Data kualitatif diperoleh dari keterangan yang disampaikan secara langsung oleh salah satu responden mengenai keberadaan layanan BK di homeschooling. Data kualitatif diperoleh dari deep interview. Dengan $\mathrm{r}$ Tabel $0,367<$ dari $\mathrm{r}$ Hitung ada 26 butir item valid. Reliabilitas 0,871 dari 50 item. Hasil layanan BK di homeschooling sangat penting dilakukan mengingat anak-anak yang berada di homeschooling membutuhkan layanan untuk dapat menjadi pengembangan diri anak. Layanan BK yang dapat diberikan dapat berupa keterampilan, bakat dan minat dan akademik. Layanan BK disesuaikan dengan kondisi anak, dari cara penyampaian, metode dan teknik layanan dan tetap menedepankan asas kerahasiaan. Layanan BK yang diberikan pada segi keterampilan 34\%, bakat dan minat 35\% dan akademik 31\%.
\end{abstract}

Kata kunci : anak berkebutuhan khusus, disabilitas, bakat dan minat, keterampilan, akademik.

\begin{abstract}
Some schools in Indonesia already have alternative schools that can help children learn according to themselves. One of them is through homeschooling. This research was conducted using a mixed method, that is by combining quantitative and qualitative data. Quantitative data were obtained from respondents who were aware of homeschooling and the need for Guidance and Couseling (BK) services in homeschooling children. The sample of respondents is 20 people representing all respondents, namely men and women in the age range of 20 - 50 years, located in the city of Tegal and surrounding areas who know the existence of homeschooling. Data is collected in a span of two months. The scale used is the type of Lickert scale that is analyzed using product moment and Alpha Krombultz. Qualitative data were obtained from information submitted directly by one of the respondents regarding the existence of BK services in homeschooling. Qualitative data were obtained from deep interviews. With $r$ Table $0.367<0 f r$ Count there are 26 valid items. Reliability 0.871 out of 50 items. The results of BK services in homeschooling are very important because children who are in homeschooling need services to be able to develop themselves. BK services that can be provided can be in the form of skills, talents and interests and academics. BK services are tailored to the conditions of the child, from the manner of delivery, methods and techniques of service and continue to prioritize the principle of confidentiality. BK services are provided in terms of skills $34 \%$, talents and interests $35 \%$ and academics $31 \%$.
\end{abstract}

Key: children with special needs, disabilities, talents and interests, skills, academics.

\section{PENDAHULUAN}

Anak-anak yang memiliki cara merespon pelajaran yang berbeda, tidak bisa disamakan dengan anak lain. Beberapa sekolah di Indonesia sudah memiliki alternatif sekolah yang dapat dilakukan. Salah satunya yaitu melalui homeschooling. Adanya homeschooling sudah lama digunakan di beberapa negara seperti di Amerika Serikat dan Inggris. Selain itu di negara ASEAN juga menerapkan homeschooling seperti di Thailand "Homeschooling in Thai society has been continuously developing and evolving as a unique learning style toward specific family goals. However, many operational problems have been encountered" (Engchun, Sungtong, \& Haruthaithanasan, 2018). Pada beberapa permasalahan anak di keluarga bahkan bisa 
ditangani melalui alternatif bersekolah di homeschooling. Bagi beberapa orang tua akan merasakan fleksibilitas pada anak yang bersekolah di homeschooling, terutama bagi keluarga yang bekerja. Homeschooling tidak hanya berlokasi di rumah masing-masing anak, namun juga bisa dilakukan pada lembaga homeschooling seperti sekolah formal pada umumnya. Berbeda dengan homeschooling di Amerika yang memiliki karakter "The mission of schools has broadened beyond academics to address risk behaviors such as substance use, delinquency, and socialization problems. With an estimated 3.4\% of all U.S. youth being homeschooled, this study examines how U.S. homeschoolers fare on these outcomes given their lack of access to these school services. Adolescents (ages 12-17) from the 2002 through 2011 National Surveys of Drug Use and Health (NSDUH) were divided based on school status (home vs. traditional schooling) and religious affiliation (stronger vs. weaker)." (Green-Hennessy, 2014). Anak-anak dengan permasalahan tertentu juga tetap mendapatkan pendidikan melalui homeschooling.

Banyak dari efek homeschooling yang bisa didapatkan. "Positive health outcomes of the foster home placement were described as a healthy and normalized weight status, a physically and socially active life, and an optimistic outlook on the future" (Regber, Dahlgren, \& Janson, 2018). Kesehatan mental anak terutama, karena beberapa anak yang bersekolah di homeschooling adalah anak berkebutuhan khusus yang tidak semua sekolah formal dapat memberikan pelayanan yang optimal, kecuali pada Sekolah Luar Biasa (SLB) yang ada baik negeri maupun swasta. Anak yang bersekolah di homeschooling juga dapat memberikan pengaruh positif pada perkembangan akademik "The purpose of this study is to measure the influence of parentchild relationship, self-esteem, and academic self-efficacy to academic stress on homeschooling students" (Mulyadi, Rahardjo, \& Basuki, 2016). Hal ini sejalan dengan tujuan pendidikan yaitu mencerdaskan kehidupan bangsa. Dengan anak bersekolah di homeschooling maka akan terjadi hubungan antara orang tua dan anak dapat menjadi lebih intens dengan adanya keterlibatan orang tua pada aktivitas belajar anak. Bahkan di Amerika juga ada beberapa pengaruh penting adanya homeschooling khusunya bagi kesehatan anak. "More than 1.8 million American children ages 5-17 are being educated at home. The percentage of school-aged children in the United States who are homeschooled increased from 1.7\% in 1999 to $3.4 \%$ in 2012. Every state has established school-entry vaccination requirements for kindergarten students, but most states exempt homeschoolers from these regulations. The goal of this study was to use qualitative methods to examine the vaccination perceptions and practices of Christian homeschooling families in Pennsylvania." (McCoy, Painter, \& Jacobsen, 2019). Makin bertambah anak-anak yang homeschooling dengan tetap memperhatikam kesehatan anak dengan adanya vaksinasi. Hal ini juga menjadi perhatian bersama, bahwa homeschooling juga memiliki fasilitas yang sama dengan sekolah pada umumya, termasuk dalam segi kesehatan anak. Beberapa layanan kesehatan tetap diberikan kepada anak "They were not statistically less likely to have health insurance, to receive annual dental care, or to receive Tetanus or Meningitis vaccinations. This research suggests that public health practitioners, medical providers, researchers, and educators should be attentive to the health care needs of homeschooled children." (Cordner, 2012).

Dasar legal homeschooling di Indonesia berdasarkan yang sudah dilaksanakan pada negara-negara lain sebagai pemahaman publik bahwa ada sekolah dari jenis formal, infromal dan non-formal salah satunya homeschooling "Homeschooling is becoming a popular alternative education to school-based education. Several factors appear to drive participants' reactions to homeschooling, most notably having a gender-related and socioeconomic orientation. If the factors that influence participants to choose homeschooling or schooling can be identified accurately, then it may be possible to use such an alternative model and regulate home school admission policies and curriculum accordingly." (Korkmaz \& Duman, 2014). Layanan bimbingan dan konseling (BK) dalam aturanya pada Permendiknas tahun 2016 menyatakan bahwa dilakukan dari jenjang SD, SMP, SMA dan SMK. Tidak terkecuali untuk homeschooling, karena anak-anak memiliki kebutuhan khusus yang perlu didampingi dalam segi psikologis. Baik untuk anak maupun orang tua yang akan mendapatkan pemahaman dari konselor homeschooling. Anak-anak yang memiliki kebutuhan khusus memang berbeda dengan anak pada umumnya, hal ini perlu perhatian khusus. Seperti pada "Neglected investigations into learning disabilities and neuropsychiatric disorders were seen in the school and healthcare sector, and better collaboration with the Social Services after a report of harm might be a potential for future improvements. Rival discourses were underlying the (in) decision regarding foster home placement." (Regber, Dahlgren, \& Janson, 2018). Bahkan anak disabilitas yang membutuhkan pembelajaran khusus akan sangat terbantu dengan 
adanya layanan homeschooling. Untuk kedepannya layanan BK dapat memberikan kebermanfaatan bagi anak dan para orang tua (parenting) anak berkebutuhan khusus. Jika tidak dijembatani oleh layanan BK di homeschooling maka akan terjadi stigma negatif pada anak berkebutuhan khusus juga sangat tinggi. Homeschooling adalah alternatif dalam pilihan orang tua untuk memberikan pendidikan "For parents of children with disabilities, stigmatization is part of everyday life. To resist the negative social and emotional consequences of stigma, parents both challenge and deflect social devaluations. Challenges work to upend the stigmatizing structure, while deflections maintain the interaction order." (Manago, Davis, \& Goar, 2017).

Selain itu juga layanan BK berfungsi untuk dapat memberikan treatment kepada anak yang memiliki permasalahan "Controlling for demographic differences, homeschoolers with weaker religious ties were three times more likely to report being behind their expected grade level and two and a half times more likely to report no extracurricular activities in the prior year than their traditionally schooled counterparts. This group was also more likely to report lax parental attitudes toward substance use. Findings suggest homeschoolers with weaker religious ties represent an at-risk group." (Green-Hennessy, 2014). Layanan yang diberikan dengan segi religius dan aktivitas ekstrakurikuler dapat menjadi alternatif layanan BK untuk anak dalam kenakalan remaja. Penanaman karakter anak menjadi hal yang penting untuk dapat memiliki tanggungjawab atas perilakunya "Responsibility character which is part of independence character can be developed by project method with several stages which should be done by lecturer (planning and getting started, projects in progress, reflection and conclusion)." (Rolina, 2014). Hal ini hanya berlaku pada anak-anak dengan kasus kenakalan tertentu. Homeschooling yang diterapkan pada remaja juga sangat membantu bagi remaja yang mengalami perilaku kenakalan seperti merokok, kecanduan alkohol dan pengguna obat-obatan terlarang "Findings indicate that homeschooled adolescents were significantly more likely to strongly disapprove of their peers drinking $(A O R=1.23)$ and trying $(A O R=1.47)$ and routinely using $(A O R=1.59)$ marijuana. Homeschooled adolescents were significantly less likely to report using tobacco $(A O R=0.76)$, alcohol $(A O R=0.50)$, cannabis $(A O R=0.56)$ and other illicit drugs and to be diagnosed with an alcohol $(A O R=0.65)$ or marijuana $(A O R=0.60)$ use disorder. Finally, homeschooled adolescents were also less likely to report easier access to illicit drugs and to be approached by someone trying to sell drugs compared to non-homeschooled peers." (Vaughn et al., 2015).

Lingkungan sosial anak sangat penting. Dukungan orang tua, keluarga dan sekitar akan sangat membantu tumbuh kembang anak. "The article presents an analysis of a number of social environments and their specific features important for children's progress. The author sets a goal: to create the conditions for a happy future for our children." (Radchenko, 2014). Orang lain yang masih berpandangan negatif bahkan stigma kepada anak tidak akan menjadikan anak rendah diri jika ditanamkan dalam diri anak kebahagiaan dalam keluarga. Penerimaan apa adanya anak akan memberikan kebahagiaan yang bermakna bagi anak. Anak akan bersemangat untuk terus melanjutkan sekolah, belajar dan bermain dengan kepercayaan dirinya. Karena pada kenyataannya banyak terjadi yang dialami anak berkebutuhan khusus dan disabilitas "We examine how parents of children with disabilities deploy deflections and challenges, and how their stigma resistance strategies combine with available models of disability discourse. Disability discourse falls into two broad categories: medical and social. The medical model emphasizes diagnostic labels and treats impairment as an individual deficit, while the social model centralizes unaccommodating social structures. The social model's activist underpinnings make it a logical frame for parents to use as they challenge disability stigma." (Manago, Davis, \& Goar, 2017). Seperti yang dijelaskan ada dua jenis stigma yaitu medis dan sosial. Jika stigma medis memang terlihat pada kondisi fisik anak yang menyebabkan terjadinya stigma sosial. Bahkan anak akan mengalami hal yang paling buruk akibat adanya stigma sosial. Maka dari itu, biarkanlah anak berada di lingkungan yang menerima dirinya apa adanya.

Akhirnya menjadi alternatif yang sangat dibuthkan bagi orang tua agar anak bisa mendapatkan pendidikan dan treatment tumbuh kembang yang baik melalui homeschooling. Perkembangan diri anak akan menjadi lebih positif dengan keberadaannya di lingkungan yang memiliki penerimaan diri seperti di homeschooling, bahkan menambah kesehatan pada diri anak "Positive health outcomes of the foster home placement were described as a healthy and normalized weight status, a physically and socially active life, and an optimistic outlook on the future." (Regber et al., 2018). Pengembangan diri anak selain self-esteem anak juga akan memiliki efikasi diri "Tutorial system perception, academic self-efficacy, and creativity are assumed as factors influencing homeschooling students' self-regulated learning." (Mulyadi, Basuki, \& Rahardjo, 2016). Khususnya pada saat pandemi COVID-19 hampir seluruh sekolah ditutup "In the midst of COVID-19, our son recently lost a patient and dear friend to pancreatic cancer; people continue to deal with and die from other diseases during the 
pandemic. Ourdaughter tries to prepare for how to quarantine herself from her husband and young children if she becomes infected with COVID-19 while she goes about her medical responsibilities caring for childbearing women and their infants." (Lowe, 2020). Akan lebih dirasakan kebermanfaatan homeschooling yaitu anak tetap belajar walau berada di rumah. Bahkan metode/ cara homeschooling diterapkan oleh sekolah-sekolah lain pada saat pandemi COVID-19 ini terjadi. Anak dan orang tua yang mengisolasi diri akan tetap dapat beraktivitas dalam pembelajaran dengan interaksi langsung dari orang tua kepada anak.

Layanan BK juga segogyanya tetap memberikan pencapaian akademik pada anak di homeschooling "The achievements of homeschooled children have been examined extensively, but the questions to be considered is whether or not the evaluation methods used were suited to the teaching and education taking place in the homeschooling context, and in particular whether these evaluation methods are compatible with the educational objectives of this framework." (Neuman \& Guterman, 2016). Dengan dasar pembekalan karakter anak "Children have the unique characteristic, and have many characters which should be developed by teacher (one of them is responsibility character)." (Rolina, 2014). Dengan memahami pentingnya anak dalam beradaptasi dengan lingkungan yang dapat menerima diri anak, layanan BK di homeschooling menjadi alternatif yang penting dilakukan. Dalam diri anak akan merasakan adanya pencapaian "...achievements of students studying in schools with those of students learning in a homeschooling environment. ...that form the basis of this study, and examines whether, and under what conditions, a comparison can be made between children attending school and those studying in the homeschooling framework." (Neuman \& Guterman, 2016).

\section{METODE}

Penelitian ini dilakukan dengan metode mixed method yaitu dengan perpaduan data kuantitatif dan kualitatif. Dalam mixed method atau penelitian campuran ini biasanya menggunakan gabungan data kuantiatif dan kualitatif untuk menghasilkan kesimpulan gabungan (Creswell, 2016: 289). Data kuantitatif diperoleh dari responden yang mengetahui adanya homeschooling dan perlunya layanan BK pada anak homeschooling. Sample responden berjumlah 20 orang yang mewakili dari keseluruhan responden yaitu masyarakat laki-laki dan perempuan dalam rentang usia 20 - 50 tahun yang berlokasi di Kota Tegal dan sekitarnya yang mengetahui keberadaan homeschooling. Pengambilan data dilakukan dalam rentang waktu dua bulan. Dari skala yang digunakan adalah jenis skala Lickert yang dianalisis menggunakan product moment dan Alpha Krombultz. Data kualitatif diperoleh dari keterangan yang disampaikan secara langsung oleh salah satu responden mengenai keberadaan layanan BK di homeschooling. Data kualitatif diperoleh dari deep interview.

\section{HASIL}

Data awal yang di peroleh saat observasi homeschooling yang dilakukan melalui informasi daring kepada informan pihak kedua dalam penelitian ini. Kurikulum yang digunakan di homeschooling menggunakan kurikulun K13. Jenjang di homeschooling ada tiga program yaitu paket A (setara SD), paket B (setara SMP) dan paket C (setara SMA). Layanan BK yang digunakan memang harus dapat merangkul anak yang memiliki kebutuhan khusus yang ada khususnya di homeschooling. Hasil yang diperoleh menunjukkan bahwa masyarakat sudah mengetahui adanya homeschooling, namun dalam kasus tertentu, seperti anak berkebutuhan khusus. Padahal anak-anak lainnya juga dapat bersekolah di homeschooling yang menunjang bakat dan minat dalam diri anak. Dengan $\mathrm{r}$ Tabel 0,367 < dari $\mathrm{r}$ Hitung adalah valid, dari butir item pernyataan skala dapat dilihat pada tabel di bawah ini.

Tabel 1. Hasil Validitas Skala

\begin{tabular}{llll}
\hline Item & r Hitung & r Tabel & Keterangan \\
\hline 1 & 0,151 & 0,367 & tidak valid \\
\hline 2 & 0,165 & 0,367 & tidak valid \\
\hline 3 & 0,171 & 0,367 & tidak valid \\
\hline 4 & 0,612 & 0,367 & valid \\
\hline 5 & 0,533 & 0,367 & valid \\
\hline 6 & 0,310 & 0,367 & tidak valid \\
\hline
\end{tabular}




\begin{tabular}{|c|c|c|c|}
\hline 7 & 0,454 & 0,367 & valid \\
\hline 8 & 0,112 & 0,367 & tidak valid \\
\hline 9 & 0,412 & 0,367 & valid \\
\hline 10 & 0,576 & 0,367 & valid \\
\hline 11 & 0,420 & 0,367 & valid \\
\hline 12 & 0,658 & 0,367 & valid \\
\hline 13 & 0,477 & 0,367 & valid \\
\hline 14 & 0,166 & 0,367 & tidak valid \\
\hline 15 & 0,503 & 0,367 & valid \\
\hline 16 & 0,182 & 0,367 & tidak valid \\
\hline 17 & 0,508 & 0,367 & valid \\
\hline 18 & 0,235 & 0,367 & tidak valid \\
\hline 19 & 0,490 & 0,367 & valid \\
\hline 20 & 0,538 & 0,367 & valid \\
\hline 21 & 0,101 & 0,367 & tidak valid \\
\hline 22 & 0,390 & 0,367 & valid \\
\hline 23 & 0,210 & 0,367 & tidak valid \\
\hline 24 & 0,461 & 0,367 & valid \\
\hline 25 & 0,111 & 0,367 & tidak valid \\
\hline 26 & 0,202 & 0,367 & tidak valid \\
\hline 27 & 0,538 & 0,367 & valid \\
\hline 28 & 0,426 & 0,367 & valid \\
\hline 29 & 0,088 & 0,367 & tidak valid \\
\hline 30 & 0,474 & 0,367 & valid \\
\hline 31 & 0,658 & 0,367 & valid \\
\hline 32 & 0,583 & 0,367 & valid \\
\hline 33 & 0,221 & 0,367 & tidak valid \\
\hline 34 & 0,183 & 0,367 & tidak valid \\
\hline 35 & 0,117 & 0,367 & tidak valid \\
\hline 36 & 0,204 & 0,367 & tidak valid \\
\hline 37 & 0,213 & 0,367 & tidak valid \\
\hline 38 & 0,352 & 0,367 & valid \\
\hline 39 & 0,273 & 0,367 & tidak valid \\
\hline 40 & 0,119 & 0,367 & valid \\
\hline 41 & 0,080 & 0,367 & tidak valid \\
\hline 42 & 0,432 & 0,367 & valid \\
\hline 43 & 0,488 & 0,367 & valid \\
\hline 44 & 0,585 & 0,367 & valid \\
\hline 45 & 0,116 & 0,367 & tidak valid \\
\hline 46 & 0,209 & 0,367 & tidak valid \\
\hline 47 & 0,106 & 0,367 & tidak valid \\
\hline 48 & 0,538 & 0,367 & valid \\
\hline 49 & 0,376 & 0,367 & valid \\
\hline 50 & 0,108 & 0,367 & tidak valid \\
\hline
\end{tabular}

Sumber: Data penelitian 2020 dengan menggunakan SPSS

Dari instrumen skala yang digunakan sejumlah 26 item pernyataan yang valid. Skala ini nantinya dapat digunakan kembali dengan jumlah 26 item untuk pengambilan data selanjutnya. Realibilitas skala yang digunakan adalah 0,871 dari 50 item pernyataan sehingga instrumen dapat diandalkan dan tingkat kepercayaan tinggi.

Tabel 2. Reliability Statistics 


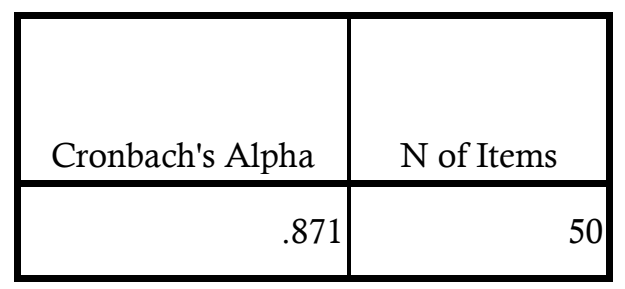

\section{PEMBAHASAN}

Hal yang menjadi fokus penelitian kali ini adalah masyarakat yang memahami adanya homeschooling dan membutuhkan adanya layanan BK di homeschooling. Banyak dari anak yang bersekolah di homeschooling berasal dari luar Kota Tegal. Hal ini dikarenakan memang minimnya sarana sekolah yang dapat memberikan layanan kepada anak berkebutuhan khusus. Banyak dari para orang tua yang kebingungan untuk dapat memilih sekolah yang diperuntukkan untuk anaknya yang berkebutuhan khusus. Hal ini seperti yang dialami oleh R1 untuk mencari homeschooling untuk anaknya "Iya mba, anak saya di homeschooling Tegal. Memang karena anak saya butuh pendampingan khusus agar dapat belajar dengan baik. Anak saya dari usia 2 tahun terlambat untuk berbicara. Sampai di usia 3 tahun masih belum dapat mengucapkan apa-apa, akhirnya saya berinisiatif untuk membawa anak saya ke homeschooling. Walau saya harus bolak balik jauh dari Kabupaten ke Kota Tegal, namun semua itu saya lakukan demi anak saya agar dapat berkembang sama dengan anak-anak yang lain. Alhamdulillah sampai sekarang anak saya di homeschooling dan sudah beraktivitas seperti teman-teman yang lain, dapat bicara dengan lancar walau terlambat." (R1, 11/03/2020).

Dari salah satu keterangan responden tersebut sangat merasa terbantu dengan adanya layanan di homeschooling untuk anaknya agar dapat bersekolah dengan baik. Informasi dari R2 "Kalau saya sedang bekerja, nanti anak saya sama siapa mba? Ini saya sama bapaknya bekerja semua, jadi saya lebih memilih homeschooling saja untuk anak saya sekolah. Pas semua berangkat kerja kita bisa sekalian mengantar anak dan saat kita pulang kerja bisa sekalian menjemput anak. Bisa leluasa juga anaknya sekolah di homeschooling." (R2, 04/03/2020). Bagi beberapa masyarakat dengan adanya homeschooling sangat terbantu sekali dalam memberikan pendidikan kepada anak. Pendidikan tidak hanya di sekolah formal, namun dapat dilakukan juga di homeschooling. Anak dapat lebih leluasa dalam belajar dan dapat menyesuaikan dengan kondisi anak.

Layanan BK di homeschooling dapat dilihat urgensinya dengan melihat presentase dari responden. Hal ini dapat menjadi rujukan bersama bahwa layanan BK di homeschooling dapat menjadi ujung tombak dalam mengembangkan diri anak. Tidak hanya mendapatkan materi pelajaran saja, namun anak juga dapat mengasah keterampilan dan mengembangkan bakat yang dimiliki masing-masing.

Tabel 1. Persentase Hasil Pernyataan Responden

\begin{tabular}{llc}
\hline No. & \multicolumn{1}{c}{ Pernyataan } & Persentase (\%) \\
\hline 1 & Aksesibilitas anak selama homeschooling & 80 \\
\hline 2 & Kebermanfaatan layanan homeschooling & 90 \\
\hline 3 & Aktivitas homeschooling bervariasi & 75 \\
\hline 4 & Perlunya Layanan BK di homeschooling & 90 \\
\hline 5 & Perkembangan motorik, afeksi dan kognisi yang baik selama homeschooling & 85 \\
\hline
\end{tabular}

Sumber: Data penelitian 2020

Maka dengan adanya layanan BK di homeschooling diharapkan dapat terus dapat mengembangkan kemampuan anak. Keterampilan yang diutamakan, karena anak dapat melakukan berbagai hal dengan keterampilan yang dimiliki. Kemudian pengembangan bakat dan minat yang dapat menjadi fokus kelebihan pada diri anak. Sehingga anak memiliki selfesteem yang baik terhadap dirinya. Dan terakhir adalah pengebangan akademik, di mana anak juga sama mendapatkan materi pekajaran namun tidak dipaksakan atau harus menjadi poin yang dilakukan anak. Pengembangan diri dalam akademik anak perlu 
dilakukan dengan cara yang menyenangkan sehingga anak dapat menangkap konten dari materi tersebut.

Gambar 1. Grafik Persentse Fokus Layanan BK di Homeschooling

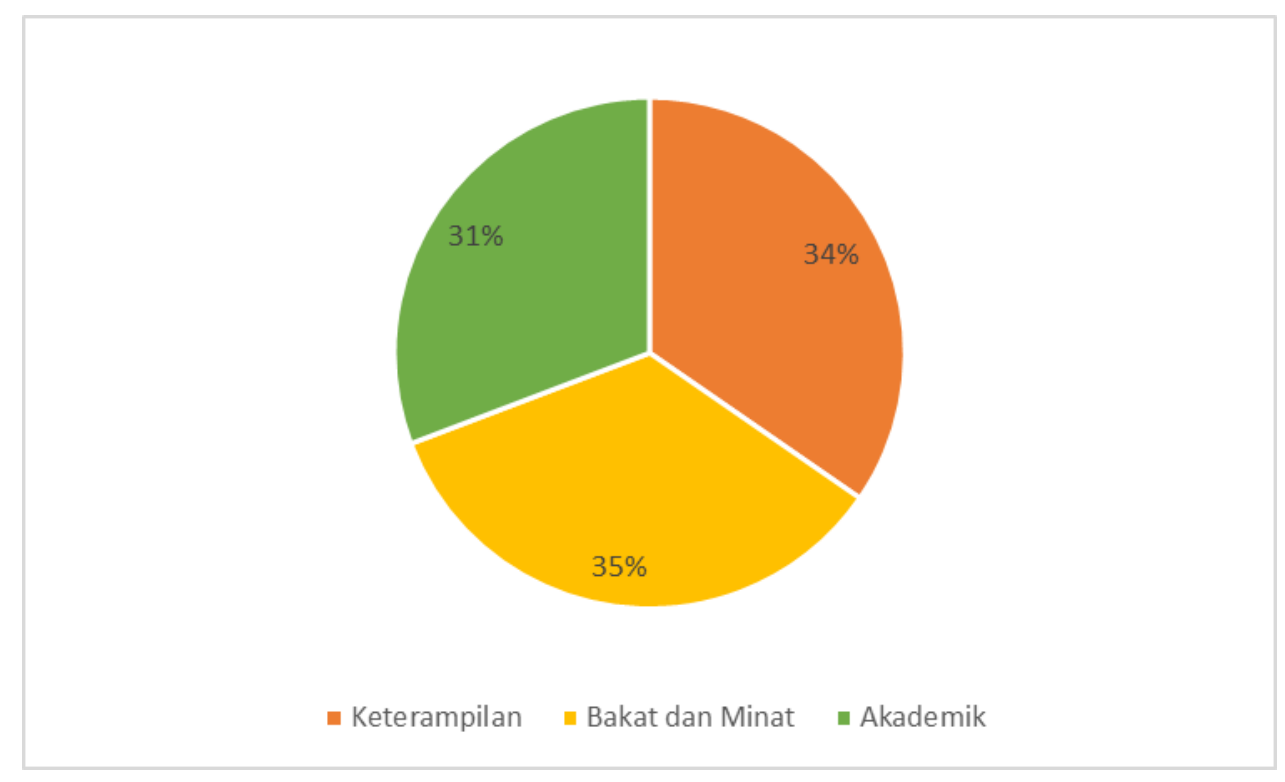

\section{SIMPULAN}

Layanan BK di homeschooling sangat penting dilakukan mengingat anak-anak yang berada di homeschooling membutuhkan layanan untuk dapat menjadi pengembangan diri anak. Layanan BK yang dapat diberikan dapat berupa keterampilan, bakat dan minat dan akademik. Layanan BK disesuaikan dengan kondisi anak, dari cara penyampaian, metode dan teknik layanan dan tetap menedepankan asas kerahasiaan.

\section{DAFTAR PUSTAKA}

Creswell, John W. 2016. Research Design Pendekatan Metode Kualitatif, Kuantitatif dan Campuran. Pustaka Pelajar: Yogyakarta.

Cordner, A. (2012). The health care access and utilization of homeschooled children in the United States. Social Science \& Medicine, 75(2), 269-273. https://doi.org/10.1016/J.SOCSCIMED.2012.02.002

Engchun, R., Sungtong, E., \& Haruthaithanasan, T. (2018). Homeschooling in Southern Thailand: Status and proposed guidelines for learning process management. Kasetsart Journal of Social Sciences, 39(3), 502-508. https://doi.org/10.1016/J.KJSS.2017.08.003

Farenga, P. (2010). Homeschooling. International Encyclopedia of Education, 214-220. https://doi.org/10.1016/B978-0-08-044894-7.01078-2

Green-Hennessy, S. (2014). Homeschooled adolescents in the United States: Developmental outcomes. Journal of Adolescence, 37(4), 441-449. https://doi.org/10.1016/J.ADOLESCENCE.2014.03.007

Korkmaz, H., \& Duman, G. (2014). Public Understanding about Homeschooling: A Preliminary Study. Procedia - Social and Behavioral Sciences, 116, 3891-3897. https://doi.org/10.1016/J.SBSPRO.2014.01.861

Lowe, N. K. (2020). Reflections on COVID-19. Journal of Obstetric, Gynecologic \& Neonatal Nursing. https://doi.org/10.1016/J.JOGN.2020.04.002

Manago, B., Davis, J. L., \& Goar, C. (2017). Discourse in Action: Parents' use of medical and social models to resist disability stigma. Social Science \& Medicine, 184, 169-177. 
https://doi.org/10.1016/J.SOCSCIMED.2017.05.015

McCoy, J. D., Painter, J. E., \& Jacobsen, K. H. (2019). Perceptions of vaccination within a Christian homeschooling community in Pennsylvania. Vaccine, 37(38), 5770-5776. https://doi.org/10.1016/J.VACCINE.2018.09.036

Mulyadi, S., Basuki, A. M. H., \& Rahardjo, W. (2016). Student's Tutorial System Perception, Academic Self-Efficacy, and Creativity Effects on Self-Regulated Learning. Procedia - Social and Behavioral Sciences, 217, 598-602. https://doi.org/10.1016/J.SBSPRO.2016.02.059

Mulyadi, S., Rahardjo, W., \& Basuki, A. M. H. (2016). The Role of Parent-child Relationship, Selfesteem, Academic Self-efficacy to Academic Stress. Procedia - Social and Behavioral Sciences, 217, 603608. https://doi.org/10.1016/J.SBSPRO.2016.02.063

Neuman, A., \& Guterman, O. (2016). Academic achievements and homeschooling-It all depends on the goals. Studies in Educational Evaluation, 51, 1-6. https://doi.org/10.1016/J.STUEDUC.2016.08.005

Radchenko, A. (2014). On the Social Environment of Child Development. Procedia - Social and Behavioral Sciences, 146, 283-289. https://doi.org/10.1016/J.SBSPRO.2014.08.130

Regber, S., Dahlgren, J., \& Janson, S. (2018). Neglected children with severe obesity have a right to health: Is foster home an alternative?-A qualitative study. Child Abuse \& Neglect, 83, 106-119. https://doi.org/10.1016/J.CHIABU.2018.07.006

Rolina, N. (2014). Developing Responsibility Character for University Student in ECE through Project Method. Procedia - Social and Behavioral Sciences, 123, 170-174. https://doi.org/10.1016/J.SBSPRO.2014.01.1411

Vaughn, M. G., Salas-Wright, C. P., Kremer, K. P., Maynard, B. R., Roberts, G., \& Vaughn, S. (2015). Are homeschooled adolescents less likely to use alcohol, tobacco, and other drugs? Drug and Alcohol Dependence, 155, 97-104. https://doi.org/10.1016/J.DRUGALCDEP.2015.08.010 